\section{EL IMAGINARIO “VERDE” $Y$ EL VERDE URBANO COMO INSTRUMENTO DE CONSUMO INMOBILIARIO: CONFIGURANDO LAS CONDICIONES AMBIENTALES DEL ÁREA METROPOLITANA DE SANTIAGO'}

Felipe Irarrázaval Irarrázaval²

\section{Resumen}

La mercantilización e instrumentalización de diversos elementos y procesos naturales ha condicionado perfectas plataformas para la acumulación de riquezas. Esto ha sido posible en la medida que existen las condiciones políticas, sociales y económicas para que suceda. Además, en el caso de las condiciones ambientales urbanas, se suma un "imaginario verde" en un amplio espectro de la población, la cual presenta un gran interés por vivir en espacios dotados de naturaleza. Estas condiciones han determinado que en las ciudades se desarrolle una desigual distribución de las condiciones ambientales, dado que cuando la gestión urbana

\section{THE “GREEN" IMAGINARY AND THE URBAN GREEN AS A HOUSING CONSUMPTION INSTRUMENT: SETTING UP ENVIRONMENTAL CONDITIONS FOR THE SANTIAGO METROPOLITAN AREA ${ }^{1}$}

Felipe Irarrázaval Irarrázaval²

\section{Abstract}

The commodification and instrumentalization of different natural elements and processes have created perfect platforms for wealth accumulation. This has been possible thanks to political, social and economic conditions. Likewise, in the case of urban environmental conditions, a "green imaginary" based on living in spaces surrounded by nature emerges in large part of the population. These conditions have triggered an unequal distribution of environmental characteristics, because when urban management is controlled by the private 
queda en manos del sector privado, sólo las elites con poder adquisitivo pueden acceder a áreas verdes y al arbolado urbano. La presente investigación busca reconocer a la naturaleza urbana como un "instrumento de consumo" inmobiliario, así como sus implicancias en la distribución de las condiciones ambientales en Santiago de Chile. Para esto se reconoce el espacio urbano en ciudades capitalistas como un eslabón dentro de las plataformas de acumulación de capital. A su vez, se integra la perspectiva de los imaginarios ofertados/empleados por el sector inmobiliario como un tema central para concretar la plataforma de acumulación.

PALABRAS CLAVE: INSTRUMENTOS DE CONSUMO, IMAGINARIO VERDE Y CONDICIONES AMBIENTALES.

Fecha de recepción: 09.03.12

Fecha de aceptación: 12.06.12

1 Proyecto FONDECYT № 1100657: “Evidencias del cambio climático en centros urbanos en Chile: Implicancias sobre los riesgos naturales y la capacidad adaptativa", 2010-2012.

2 Chile. Geógrafo Universidad de Chile. Profesor asistente del Departamento de Historia y Geografía, Universidad Metropolitana de Ciencias de la Educación. Correo electrónico: irarrazaval.f@ gmail.com

74 revista invi № 75 / Agosto 2012 / Volumen № 27: 73-103 sector, the elite is the only group with access to green areas. This research seeks to identify urban nature as a real estate "consumption instrument", as well as the implications of this concept on the distribution of the environmental conditions in Santiago de Chile. To this effect, the urban space in capitalist cities is regarded as a link within the platforms for wealth accumulation. In addition, this paper shows the perspective of offered/used imaginaries in the housing sector as a central issue to complete this accumulation platform.

\section{KEY WORDS: CONSUMPTION INSTRUMENTS, GREEN} IMAGINARY AND ENVIRONMENTAL CONDITIONS.

1 FONDECYT Project 1100657: "Evidences of climate change in Chilean urban centers: Implications about natural risks and adaptive capacity, 2010-2012".

2 Chile. Geographer, Universidad de Chile. Assistant Professor, Departamento de Historia y Geografía, Universidad Metropolitana de Ciencias de la Educación. Email: irarrazaval.f@gmail. com 


\section{Introducción: la desigual distribución social de las condiciones ambientales en el área metropolitana de Santiago}

El medio ambiente urbano constituye una transformación de la naturaleza, que representa extensos procesos sociales, políticos y económicos ${ }^{3}$ que se articulan material e inmaterialmente en la ciudad, así como en su dinamismo metabólico, propio de un espacio humanamente producido. Las desigualdades socio-ambientales, materializadas en las distintas morfologías que componen la ciudad, evidencian estos procesos ${ }^{4}$, así como los modelos adoptados, vividos, o bien impuestos en ella.

La desigual distribución social de las condiciones ambientales en la ciudad toma importancia en la medida que se entienden estas como la ausencia o presencia de un elemento físico determinado, la cual tiene respuestas concretas en sus habitantes ${ }^{5}$. Por ejemplo, el habitar zonas con mayor presencia de áreas verdes implica una serie de beneficios

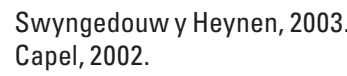

Marans, 2003. para la población como la regulación de los riesgos hidrometeorológicos y de remoción en masa, la captación de material particulado y la depuración de la columna de aire, la concentración de biodiversidad (especialmente avifauna) ${ }^{6}$, así como también todas las ventajas paisajísticas, espirituales y culturales que implica. Por otro lado, la distribución del clima urbano, más específicamente la concentración de altas temperaturas, implica una mayor susceptibilidad ante enfermedades cardiovasculares y respiratorias, a la vez que también aumentan las enfermedades infecciosas y las asociadas a contaminación atmosférica en periodos cálidos ${ }^{7}$.

El Área Metropolitana de Santiago (AMS) presenta una serie de problemáticas respecto a las condiciones ambientales, propias de la mayoría de las ciudades, no obstante su particularidad radica en la desigual distribución de estas problemáticas, así como de las amenidades ambientales, entre los habitantes que la componen. Se puede citar como ejemplo la distribución de las áreas verdes ${ }^{8}$, la calidad del aire ${ }^{9}$, cercanía a vertederos ${ }^{10}$, exposición a riesgos naturales y concentración de altas temperaturas ${ }^{11}$. Todos los casos concluyen que los

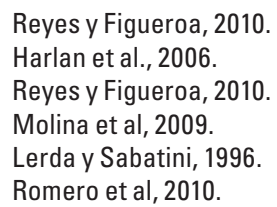


estratos sociales altos son los que se emplazan en las zonas de mejores condiciones ambientales, en desmedro de los estratos sociales bajos que son relegados a habitar en espacios que no poseen buenas condiciones para su salud y bienestar en general.

Los grupos de estratos sociales altos tienden a concentrar funciones y servicios ambientales al interior de la ciudad, lo que determina a su hábitat como un espacio de atractivas condiciones ambientales. La evidencia de esto se puede observar en sus viviendas de gran tamaño ubicadas en sitios de considerables dimensiones, lo que les permite instalar jardines, piscinas o áreas verdes; además del acceso a calles arboladas, parques y plazas" $^{12}$. Si bien "las condiciones ambientales (físicas y sociales) pueden ser mejoradas en ciertos lugares $y$ para ciertas personas, ellas a menudo conducen hacia la degradación de las condiciones sociales y físicas y de sus cualidades en otros lugares, ya sea dentro de la ciudad, o bien entre distintas ciudades"13. En este sentido es fundamental considerar que la generación y mantención de zonas de buenas condiciones ambientales en el AMS, por lo general, es cubierta por los grupos de alto nivel adquisitivo ${ }^{14}$, los que canalizan sus recursos hacia el sector privado en

12 Perkins y Heynen, 2004; Heynen, 2006 y Fuentes et al., 2011.

13 Swyngedouw y Heynen, 2003, p. 909.

14 Romero y Vázquez, 2005. búsqueda de entornos amenos. Por su parte, los sectores más vulnerables dependen principalmente de las acciones públicas para desarrollar las condiciones de su hábitat ${ }^{15}$.

Lo anterior se relaciona estrechamente con el modelo neoliberal impuesto durante el régimen militar, el cual en materias urbanas se tradujo fundamentalmente en la Política Nacional de Desarrollo Urbano (PNDU) de 1979 y 1985. Entre otras cosas, en esta se determina que es el sector privado, principalmente inmobiliario, el encargado más importante de la gestión urbana dentro de las ciudades ${ }^{16}$. En líneas generales se puede afirmar que en estas políticas se plasman las ideas fundamentales que sustentan el actual sistema del mercado de suelo, como son la consideración de éste como un bien no escaso, y por ende la asignación de su uso principalmente sobre la base de su rentabilidad, y el reconocimiento del Estado subsidiario para poder asegurar la dotación mínima de vivienda social y el equipamiento apropiado para sustentar los proyectos inmobiliarios privados ${ }^{17}$.

El problema fundamental radica en que el mercado inmobiliario no ofrece muchas oportunidades de elección a las clases de menores ingresos y se crea una división social del espacio urbano ${ }^{18}$. En

15 Ibíd.

16 Mattos, 2004

17 Trivelli, 2006.

18 Marcuse y Van Kempen, 2000 en Janoschka, 2002. 
efecto, el mercado inmobiliario como empresa privada no tiene obligación alguna de desenvolverse altruistamente, en la medida que su finalidad es generar utilidades. Por lo tanto, si el mercado inmobiliario no actúa altruistamente y el Estado se restringe respecto a su protagonismo en la gestión urbana, en esta materia la sociedad en su conjunto no tiene quién la valore ${ }^{19}$.

A raíz de lo anterior, las condiciones ambientales en el AMS se limitan a las dinámicas del mercado inmobiliario, quien crea elementos determinantes para las condiciones ambientales, internaliza las condiciones del entorno y externaliza aquellos elementos contraproducentes para su actividad. Por lo tanto, se puede afirmar que aspirar a una homogeneidad en cuanto a la distribución de las condiciones ambientales del AMS es prácticamente contradictorio con el modelo político-ideológico imperante en el país. En palabras de Reyes" ${ }^{20}$ "la sustentabilidad ambiental se contrapone a actividades cuyas rentabilidades provienen en buena parte de la inexistencia de mecanismos que obliguen a internalizar externalidades negativas, con lo cual no hay incentivos, por ejemplo para disminuir la contaminación atmosférica o la producción de basuras. También se

19 Santos, 2004.

20 Reyes, 2004, p. 190. contrapone a actividades basadas en la apropiación de externalidades positivas, como aquellas vinculadas al mercado inmobiliario, que internaliza los beneficios de los mejoramientos viales y de los cambios normativos, sin un pago por las plusvalias generadas por la sociedad en su conjunto".

Es indudable que las buenas condiciones ambientales del AMS se encuentran acaparadas por una elite social, así como también ha sido bastante evidenciado ${ }^{21}$. No obstante, en este escrito se quiere afirmar y demostrar que las condiciones ambientales en el AMS, o bien ciertos elementos que las condicionan, han sido acaparadas por una elite social en la medida que el sector inmobiliario las ha canalizado hacia ellos mediante la instrumentalización de las condiciones ambientales para fomentar el consumo de sus bienes comerciales. Es fundamental explorar hacia argumentos explicativos de la distribución de las condiciones ambientales en el AMS, "en la medida que el capitalismo y la mercantilización develan y esconden múltiples procesos socio-ecológicos de dominación/subordinación y explotación/represión que convierten a la ciudad en un proceso socio-ambiental caleidoscópico y metabólico".22 


\section{Instrumentalizando la vegetación urbana para acumular riquezas}

En la medida que el capitalismo se consolidó, a la apropiación de elementos y procesos naturales pasó a asignarles valores de cambio, a convertirlos en mercancías, lo que en primera instancia se expresó esencialmente en materias primas (madera, minerales, productos agrícolas, combustibles fósiles, etc. $)^{23}$. En ese sentido se puede sostener que los elementos y procesos naturales pasaron a ser mercantilizados, al ser ingresados al mercado, comprimiendo el valor de uso y el valor de cambio bajo un solo valor. Este fenómeno representa la mercantilización fundamental de la naturaleza, la cual no obstante comienza a tornarse explícita por la inserción en el mercado de una serie de elementos naturales al interior de la ciudad en la década del 80.

Durante esta década, las demandas de los movimientos ambientales logran impulsar una serie de políticas públicas de regulación y legislación respecto a temáticas ambientales orientadas a resolver cómo regular la degradación del medio natural mediante la aceptación de un margen permisible de su destrucción ${ }^{24}$, logrando situar estas temáticas

23 Smith, 2007

24 Ibíd. en las agendas de estado. Esto se contextualiza en el "Capitalismo Verde" y la "Crisis Ecológica", que buscan suavizar los impactos de la explotación de la naturaleza mediante soluciones de mercado, que favorecen el proceso de acumulación capitalista, intensificando y profundizando su penetración sobre la naturaleza ${ }^{25}$. Ejemplo de esto es el mercado de bonos de carbono, los permisos de emisiones contaminantes transables, o la compensación por daño ambiental.

Llevando lo anterior al plano de las condiciones ambientales urbanas, Heynen ${ }^{26}$ asocia la distribución social de estas con la mercantilización de la vegetación urbana, así como al debilitamiento de la gestión del arbolado urbano por parte del sector público. Heynen ${ }^{27}$ señala que los elementos y procesos ecológicos son producidos en el espacio urbano como instrumentos de consumo, que al realzar la belleza paisajística del entorno estimulan la comercialización de las viviendas del sector. Esta idea toma mayor sentido si se ve el interés de ciertos grupos de la población por habitar espacios más cercanos a la naturaleza y de mejor calidad ambiental. En ese aspecto las buenas condiciones ambientales podrían estar siendo instrumentalizadas por el sector privado para fomentar el consumo de sus productos. 
Harvey $^{28}$ sostiene que ciertas mercancías tienen un rol análogo en el campo del consumo, al que desempeña el capital fijo en el proceso de producción. Alude a que éstas no son reducidas directamente, sino que sirven como instrumentos de consumo ${ }^{29}$. Los instrumentos de consumo, que se pueden agrupar en un fondo de consumo, se determinan en función del uso que se les otorgue y no en su condición material. Por ejemplo, un televisor es una mercancía pero sirve para fomentar otros consumos mediante la publicidad; lo mismo sucede con la cuchillería, utensilios de cocina, viviendas, etc.

Harvey señala cuatro puntos iniciales respecto al fondo de consumo, de los cuales en este trabajo se considera atingente mencionar $\operatorname{dos}^{30}$ :

I) Respecto a la obsolescencia de los instrumentos de consumo, se debe mencionar que ésta se encuentra asociada a modas, caprichos pasajeros y al deseo de exhibir condiciones de alto nivel social, condiciones que son determinadas por el capital.

II) La distinción entre los "artículos de primera necesidad" y "artículos de lujo" dentro del fondo de consumo, debido a que para la burguesía estos tienen ramificaciones muy diferentes a las del fondo de consumo que se emplea para la reproducción de la fuerza de trabajo, por lo que se debe hacer esta distinción entre los diferentes instrumentos de consumo.

Respecto a estos dos puntos, y asumiendo a las condiciones ambientales urbanas, o bien a la vegetación urbana, como instrumentos de consumo, se desprenden dos afirmaciones. Primero, que todo instrumento de consumo tiene una conexión cultural asociada a modas o caprichos pasajeros. Y segundo, que la instrumentalización de la vegetación urbana para el consumo inmobiliario, al no ser un "artículo de primera necesidad" se enfocará hacia los grupos sociales de mayor poder adquisitivo, o bien a aquellos que posean un nivel alto de aspiraciones y potencial de endeudamiento.

\section{El "imaginario verde": capricho cultural de la naturaleza urbana}

Retomando el primero de los dos puntos mencionados en el párrafo anterior, se debe reconocer que desde que existen las ciudades se han valorado las buenas condiciones ambientales, o bien los espacios naturales en sí mismos, dado que en un amplio sentido representan la antítesis de la ciudad.
28 Harvey, 1990, p. 234

29 Ibíd.

30 Ibíd. 
Esto queda de manifiesto inclusive en la antigua Roma, en la costumbre propia de los patricios de dividir la vida entre el domus (urbano) y la vila (rural) $^{31}$

En un principio, lo atractivo se encuentra en la oportunidad de aislarse de las condiciones propias de la ciudad en un ambiente agradable, libre de aquella carga social que la ciudad implica; "aislarse como un monje y vivir como un príncipe" 32 . Frykman y Lôfgren ${ }^{33}$ señalan que en la clase media sueca también se presenta el fenómeno de la valoración de los espacios naturales bajo el marco de alejarse de los quehaceres de la ciudad en un entorno natural, orientándose a encontrar el silencio y contemplación en lo que prácticamente se presenta como un ritual.

Urteaga $^{34}$ relata que en España para el siglo VXIII se deja de reconocer lo natural como algo mecanicista y estático, y se sucede a reconocer en ella un goce paisajístico. Por otro lado, Müllauer-Seichter ${ }^{35}$ señala que, para el caso de Madrid, los espacios naturales dentro de la ciudad cumplían fundamentalmente un rol sociocultural, dado que los grandes parques representaban en realidad lugares de esparcimiento y encuentro, espacios donde los

31 Dematteis, 1998.

32 Mumford, 1963 en Dematteis, 1998, p. 225.

33 Frykman y Lôfgren, 1987.

34 Urteaga, 1987 en Müllauer-Seichter, 2001.

35 Ibíd.

80 revista invi № 75 / Agosto 2012 / Volumen № 27: 73-103 actores sociales podían verse y dejarse ver. No obstante, el autor sostiene que estos espacios se producían para determinados grupos sociales de elite.

A las condiciones mencionadas anteriormente, se debe agregar, como se precisó en el punto anterior, que durante el "Capitalismo verde" y la "Crisis ecológica" en la década del 80, asociado al acelerado avance de la tecnología y la urbanización, grupos determinados de la población iniciaron la búsqueda de espacios más cercanos a la naturaleza ${ }^{36}$. Si bien en esta instancia se valora la naturaleza por todas las condiciones ambientales, sobre la base de lo señalado por Mellizo ${ }^{37}$, se puede pensar que el principal rol que se busca en ella es un escape a las condiciones urbanas.

Aunque el interés por la naturaleza ha sido un continuo en la historia urbana, se debe mencionar que trae consigo una fuerte connotación social asociada a la realeza y a la clase burguesa. En ese sentido los grupos medios comienzan a replicar los modos de vida de los grupos altos respecto a la naturaleza. La costumbre de la burguesía latina que ejercía su modo de vida dualmente entre la domus y la vila comienza, durante el medioevo, a ser replicada por estratos sociales medios que empiezan a adquirir 
predios rurales en torno a ciudades como Génova, Florencia, Perugia, Marsella, Montpellier y Toulou$\mathrm{se}^{38}$. Consiguientemente, en el Renacimiento comienzan a construirse diferentes obras al interior de las ciudades, periodo en el cual se materializan una serie de proyectos que comprendían villas y jardines para las clases acomodadas, ubicadas fundamentalmente en los bordes de las ciudades, a la vez que se insertan los parques privados en los proyectos urbanos de la burguesía ${ }^{39}$. De aquí en adelante, la población con poder adquisitivo consolida la lógica de replicar los gustos burgueses en cuanto a espacios naturales urbanos ${ }^{40}$.

Los antecedentes expuestos pueden ser considerados como distantes cronológicamente, sin embargo, en realidad son aportes de suma importancia para analizar los contrastes sociales preponderantes en las condiciones ambientales de AMS, los cuales invitan a complejizar las investigaciones en la materia. Las cualidades del espacio y la valoración de éstas se basan en las formas de pensamiento que tienen los seres humanos con su espacio. Por lo tanto, las ideas, representaciones e imágenes que sean introducidas en él son fundamentales ${ }^{41}$. De ahí la importancia de reconocer lo "verde" dentro de un imaginario, dado que éste refleja parte de las

$\begin{array}{ll}38 & \text { Dematteis, } 1998 . \\ 39 & \text { Miller, 1997. } \\ 40 & \text { Miller, 1997, p. } 84 . \\ 41 & \text { Ríos y Pírez, } 2008 .\end{array}$

subjetividades individuales y colectivas ${ }^{42}$. Es fundamental considerar las representaciones como un eje central de la noción de imaginario, más aún el proceso de conformación de ese imaginario ${ }^{43}$. En esta línea, a continuación citaré algunos casos que tratan la representación de lo "verde" en el espacio urbano latinoamericano, ligándolo estrechamente a fenómenos relativamente recientes impulsados por el capital privado.

Para Girola ${ }^{44}$ existe un imaginario verde urbano en los proyectos inmobiliarios en la ciudad de Buenos Aires. Para esta afirmación se basa en dos realidades socio-territoriales diferentes planteadas por Zukin ${ }^{45}$, las que representan dos modalidades residenciales que constituyen las ciudades: una ciudad moderna histórica que reproduce paisajísticamente las obras del sector público y constituye el hábitat de sectores populares y asalariados de clase media y media-baja, mientras que existe otra ciudad moderna reciente que se materializa en espacios urbanos cerrados impulsados por el capital privado y destinados a población de nivel socio-económico medio-alto y alto. Girola ${ }^{46}$ estudia el imaginario de pureza existente en el barrio cerrado de Pilar en contraposición del imaginario de contaminación y peligro existente en Villa Soldati, ambos casos en la

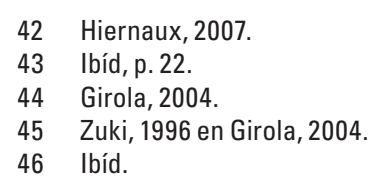

revista invi № 75 / Agosto 2012 / Volumen № 27: 73-103 
ciudad de Buenos Aires ${ }^{47}$. La autora sostiene que la naturaleza es uno de los principales referentes de la producción simbólica de las urbanizaciones cerradas bonaerenses, "la naturaleza — asociada a la existencia de espacios verdes compartidos donde realizar actividades recreativas y deportivas - se presenta como un ingrediente central de los imaginarios y vivencias de sus habitantes $^{248}$. Esto en parte lo asocia a que este tipo de proyectos en Buenos Aires se emplazaron en zonas periféricas abandonadas por los estratos sociales altos, por lo que surge la naturaleza como un elemento que dota de pureza el espacio e incita a su revalorización. "En síntesis, la construcción de las sub-urbanizaciones cerradas periféricas como zonas verdes es producto de un imaginario de la pureza, anclado en la naturaleza como estrategia generadora de espacios 'sanos' y de relaciones sociales aparentemente 'armónicas', que oscurece los muchos conflictos que se generan dentro de este tipo de urbanizaciones ${ }^{49}$ ". A su vez, sostiene que esta instrumentalización de "lo verde" reconfigura la condición tradicional de la naturaleza como lugar de encuentro público, como proyecto político colectivo, en pro de un proyecto residencial "al servicio de la conformación de un espacio privado que acentúa la segregación y que responde a un proceso de alta selectividad social" 50 .

47 Girola, 2004. Si bien la comparación realizada por la autora es sumamente interesante, en este caso me centraré en lo planteado respecto al barrio Pilar por su atingencia temática.

48 Ibíd, p. 103.

49 Ibíd, p. 106.

50 Ibíd, p. 105

82 revista invi № 75 / Agosto 2012 / Volumen № 27: 73-103
Por su parte, Malizia ${ }^{51}$ también se basa en las urbanizaciones cerradas como fenómeno en estudio. Sobre ellas señala que son una moda en propagación desde el centro a la periferia, la cual asigna nuevos valores y estilos de vida junto a una aceleración en las dinámicas de circulación del capital. La autora indica que en grandes ciudades la noción de seguridad es lo que se menciona con mayor frecuencia dentro de las investigaciones asociadas, no obstante para el caso de las ciudades intermedias prevalece una idea asociada a relacionarse de forma más directa con la naturaleza por parte de sus habitantes. En la misma línea afirma que en las ciudades intermedias las urbanizaciones cerradas se ubican en las periferias, cerca de espacios verdes, de buenas condiciones ambientales y paisajísticas $^{52}$. De todos modos, en la tipología de urbanizaciones cerradas que propone la autora, en ciertas clasificaciones los jardines o áreas verdes son elementos constitutivos de dicha forma de urbanización (Torres jardin o Clubes de campo, por ejemplo).

Del mismo modo, Ríos y Pírez ${ }^{53}$ afirman que la expansión urbana de Buenos Aires desde fines de siglo XX hasta ahora, bajo la forma de urbanizaciones cerradas, emplea firmemente la noción de

51 Malizia, 2010

52 Ibíd.

53 Ríos y Pírez, 2008. 
"desarrollo urbano sustentable". Esto lo vinculan al desarrollo del proyecto inmobiliario Nordelta en el municipio de Tigre, en donde el "imaginario verde" y la seguridad son elementos centrales. "Estas transformaciones del espacio pueden entenderse ante el contexto de un nuevo mercado residencial (oferta de barrios cerrados y demanda de las nuevas clases media-altas) dentro del 'imaginario verde' y el valor de la seguridad de los años noventa..." $"$. Cabe resaltar que los autores enfatizan que un principio rector en la utilización del imaginario verde en los proyectos inmobiliarios, es la acumulación del capital por parte de sus promotores. "La necesidad de divulgar a las urbanizaciones cerradas como 'espacios verdes', de 'vida saludable', lejos del contaminado centro metropolitano, enmascara la obtención de grandes lucros... Asimismo, la valorización de las cualidades 'naturales' únicas de esos espacios en un contexto de creciente sensibilidad ecológica, permite la obtención de lucros que se obtienen de una renta monopólica" ${ }^{55}$.

La narrativa del paisaje en Santiago no puede dejar de ser pensado desde quienes lo están componiendo, y si pensamos en un desarrollo urbano basado en el sector privado, en quienes interactúan mediante relaciones de mercado (productores-consumidores). En esos términos, lo señalado por Ríos y Pírez ${ }^{56}$ toma gran sentido, dado que los principales productores

54 Ibíd, p. 113.

55 Ibíd, p. 116.

56 Ríos y Piréz, 2008. del espacio urbano del AMS son capitales privados inmobiliarios, hecho definido políticamente. Desde la publicidad que realizan estos proyectos se puede visualizar la representación que buscan posicionar en la población, o que bien la población tiene posicionados y el sector privado busca explotar como instrumento de consumo. "Sin embargo, parecería que los grupos dominantes tienen un papel decisivo en la construcción de los imaginarios urbanos actuales: por una parte, imprimen su sello sobre la producción de los medios masivos de comunicación que orientan ciertos imaginarios por el bombardeo de imágenes que ofrecen ${ }^{57}$ ".

Los imaginarios, y especialmente las representaciones, en estas materias deambulan permanentemente en la publicidad inmobiliaria, espacio de diálogo por excelencia entre productores y consumidores en la actualidad. "Los imaginarios del miedo $y$ del consumo se reflejan fielmente en los anuncios de las revistas enfocadas al mercado inmobiliario ${ }^{58 "}$.

\section{Planteamiento de la investigación}

Si bien existen varios autores que dan cuenta de las desigualdades en relación a las condiciones ambientales en el AMS, no se ha indagado lo

57 Hiernaux, 2008, p. 27.

58 López, 2008, p. 142. 
suficiente respecto a sus orígenes. Considerando lo señalado por Romero y Vásquez ${ }^{59}$, de que los grupos de nivel socioeconómico más alto concentran mejores condiciones ambientales porque están interesados y son capaces de financiarlas en un contexto donde la gestión urbana recae en gran medida en el sector inmobiliario, se puede pensar que la diferenciación ambiental existe en función de las relaciones de mercado.

En base a lo anterior debiese ser posible constatar diferencias en los precios de las propiedades para las diferentes zonas ambientales del AMS. De ser correcta esta afirmación, las propiedades emplazadas en zonas de mejor calidad ambiental debiesen tener un valor más elevado. Si bien las variables pueden indicar relación, es necesario agregar afirmaciones para identificar a la naturaleza urbana como instrumento de consumo inmobiliario. Por lo que de forma complementaria es analizada la propaganda de los proyectos inmobiliarios en función de atributos relacionados a las condiciones ambientales. En base a estas dos relaciones se espera construir el argumento respecto a que las condiciones ambientales operan como instrumentos de consumo para el mercado inmobiliario.

El presente artículo busca ser un aporte exploratorio que entregue argumentos adicionales para

59 Romero y Vásquez, 2005. comprender la relación que se ha sostenido entre la desigual distribución espacial de las condiciones ambientales en la ciudad de Santiago, destacando el rol del sector inmobiliario en la generación de tales desigualdades dentro del contexto neoliberal en que se sitúa la gestión urbana en Chile.

\section{Metodología}

Dada la considerable extensión del AMS, en la medida que se espera trabajar a una escala medianamente detallada de análisis, se abordó como muestra representativa de la totalidad del AMS las comunas de Las Condes, La Reina, Nuñoa, Providencia, Santiago, Quinta Normal, Lo Prado, Estación Central, Cerro Navia y Pudahuel. Esto en función de los resultados de otros autores ${ }^{60}$, que aluden a la potente diferenciación Oriente-Poniente existente en Santiago, por lo que se toma dicha gradiente en el eje central de la ciudad.

\section{IDENTIFICACIÓN Y CLASIFICACIÓN DE ZONAS DE DIFERENTES CONDICIONES AMBIENTALES}

Se procederá a clasificar la totalidad del área de estudio para seleccionar ciertas categorías, que serán aquellas de connotación residencial y de considerable representatividad superficial dentro

60 Mattos, 2004; Peña, 2008; Molina et al, 2009; Escobedo et al, 2006 y Reyes y Figueroa, 2010.

ARTÍCULO: El imaginario "verde" y el verde urbano como instrumento de consumo inmobiliario: configurando las condiciones ambientales del área metropolitana de Santiago /

Felipe Irarrázaval Irarrázaval 
del área de estudio. Se clasifica sobre una tipología de zonas termales homogéneas adaptada de Stewart y Oke ${ }^{61}$. La tipología de fotointerpretación se basa a grandes rasgos en la clasificación sobre dos criterios. Primero es la densidad de construcción, donde se categoriza entre alta y baja densidad. Segundo es la altura de edificación, donde se promueven tres categorías (alta, media y baja altura), a las cuales se agregarán categorías mixtas (alta y media altura y media y baja altura) debido a la complejidad observada en el área de estudio. La tipología se ilustra en la Figura 1. De ese modo se generan cruzando estos dos factores 10 categorías principales, las cuales son complementadas con tres categorías de carácter más específico, como lo son la urbanización dispersa y las zonas industriales. Por otro lado se agregan categorías para espacios no urbanizados (cobertura arbórea dispersa, cobertura vegetal rasante y suelo desnudo). La tipología es aplicada mediante fotointerpretación, escala $1: 10.000$.

Los resultados obtenidos fueron evaluados bajo los parámetros de cobertura vegetal y temperaturas de emisión superficial, entendiendo a ambos como variables de la calidad ambiental. Estos fueron obtenidos de una imagen ASTER. La temperatura de emisión superficial se obtuvo del subsistema TIR, considerando un valor de emisividad inicial de 0,98 , el cual posee una resolución espacial de

61 Stewart y Oke, 2009.

\section{FIGURA 1. TIPOLOGÍA DE FOTOINTERPRETACIÓN ADAPTADA DE STEWART Y OKE (2009).}

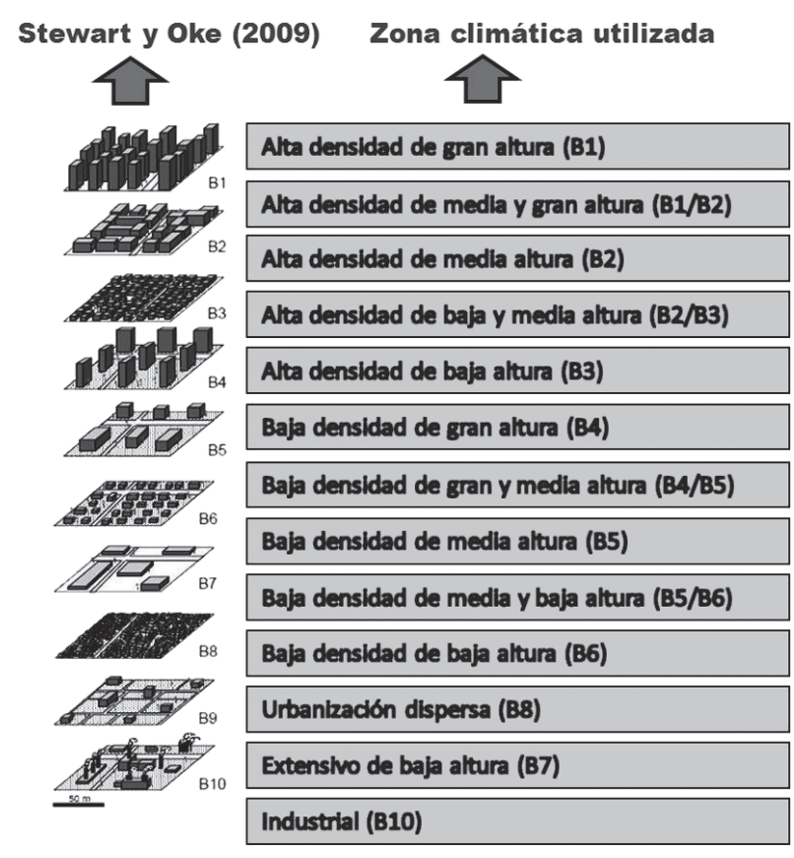

Elaboración propia en base a Stewart y Oke (2009).

$90 \mathrm{mts}^{62}$. Por otro lado, la cobertura vegetal fue obtenida mediante clasificación supervisada, empleando el clasificador blando UNMIX, sobre la información extraída del subsistema VNIR, el cual posee una resolución espacial de 15 mts.

62 Guerra, 2009, p.83. 


\section{RELACIÓN DEL MERCADO INMOBILIARIO CON LAS ZONAS TERMALES}

Con las categorías seleccionadas, se procede a evaluar los valores de las propiedades para cada una de estas, los cuales se buscaron en base de datos de portal inmobiliario (www.portalinmobiliario.com). Los puntos de muestreo se definieron con la finalidad de tener una representatividad superficial de cada zona del 10\%, manteniendo como umbral mínimo una muestra por 100 Has. Con la cantidad de puntos para cada clase definida se procedió a distribuirlos, mediante un muestreo aleatorio estratificado.

Para analizar las condiciones ambientales como instrumento de consumo para el mercado inmobiliario en el área de estudio, se empleó, a grandes rasgos, un análisis de contenido cualitativo, sobre la base de 20 proyectos inmobiliarios nuevos que aludieran a condiciones ambientales en sus nombres o atributos ofertados. Se trabajó sobre folletos publicitarios, propaganda en medios escritos (revistas) y sitios web. En base a Cáceres ${ }^{63}$ se consideraron las labores propias de las tres primeras etapas de análisis de contenido cualitativo: selección de un modelo de comunicación, pre-análisis y de la definición de unidades de análisis.

El modelo de comunicación se debe orientar a definir la postura teórica sobre el contenido por analizar, estableciendo suposiciones que guíen el análisis. Para este caso se afirma la utilización de lo "verde" para fomentar el consumo de un producto inmobiliario, no obstante que esta instrumentalización puede ser variada en su trasfondo empleando diferentes aportes de lo natural.

El pre-análisis implica un primer intento por organizar la información y responder a tres tópicos: recopilación de información, identificar guías y establecer indicadores. Si bien el trabajo se basó en la publicidad inmobiliaria, la que fue el material objetivo de recopilación de información, ésta fue acotada a aquella que evidenciaba ofrecimientos "verdes", para de ese modo acotar el universo de análisis. Finalmente fueron reconocidos tres indicadores de lo señalado en el modelo de comunicación. Primero son los nombres de los proyectos, dado que estos frecuentemente aluden a elementos naturales o relacionables con la naturaleza (jardín, parque, viñedo, etc...). Segundo son los atributos ofrecidos por cada proyecto, dado que usualmente ofrecen vivir cerca de la naturaleza, áreas verdes o aire limpio. Tercero es que en las imágenes empleadas por las inmobiliarias normalmente resaltan los colores verdes, agregando árboles y cielo azul, entre otras cosas, que ilustran gráficamente buenas condiciones ambientales.

Las unidades de registro empleadas recogen para los dos primeros indicadores aquellas de tipo gramatical desde una perspectiva semántica, es decir,

63 Cáceres, 2003. 
se realizan interpretaciones sobre aquellos elementos gramaticales que se busca evaluar. Respecto al tercer indicador, en el cual se analizarán las imágenes dentro de la publicidad, se procederá a aplicar técnicas propias del análisis de contenido de imágenes publicitarias. Se evaluará combinando el análisis de aquellos elementos denotativos de la imagen (elementos principales, color y composición), con aquellos connotativos (interpretación), manteniendo el modelo de comunicación establecido inicialmente.

\section{Resultados: distribución de condiciones ambientales}

Tras aplicar la tipología al área de estudio mediante fotointerpretación, y evaluar ésta mediante el porcentaje de cobertura vegetal y la temperatura de emisión superficial, se concluyó que cinco de estas categorías (considerando las de uso residencial en función a la problemática planteada) tenían mayor presencia superficial, además de ser considerablemente diferentes respecto a su morfología, así como también presentaron diferencias en cuanto a las variables ambientales aplicadas. En la Tabla 1 se presenta un resumen de cada una de estas.

En la Figura 2 se muestra la distribución de estas zonas. En líneas generales se puede decir que las zonas termales de baja altura (B3, B6 y B9), presentan mayor porcentaje de cobertura vegetal. Por otro lado, las zonas que presentan densidades más bajas presentan mayores porcentajes de cobertura vegetal (B5, B6 y B9), así como también presentan temperaturas de emisión superficial más bajas. Las temperaturas de emisión superficial son más altas en las zonas de mayor densidad de construcción, así como también en las zonas de menor altura (B6 y B9 por ejemplo). Esto último se explica fundamentalmente por el efecto de la sombra sobre la imagen satelital.

Las zonas de baja densidad (B5 y B6) y especialmente la de urbanización dispersa (B9), son las que se caracterizan por poseer mejores condiciones ambientales. En ese sentido se puede afirmar que las zonas de mejores condiciones ambientales se ubican fundamentalmente en el sector oriente del área de estudio, mejorando gradualmente hacia el pie de monte de la ciudad. Esta gradiente se puede observar en sentido Oeste-Este en la totalidad del área de estudio, dado que al Oeste se concentran las zonas B3, al centro las B2 y B5, en el Este las zonas B6 y al extremo Este las zonas B9.

\section{Relación de zonas termales y valores de propiedad}

Los precios obtenidos dentro de cada zona termal se diferencian considerablemente respecto a sus promedios. Los promedios más elevados los tienen las zonas termales de baja densidad de baja altura (B6) y urbanización dispersa (B9), las cuales en su 


\section{TABLA 1: CARACTERIZACIÓN DE ZONAS TERMALES HOMOGÉNEAS.}

\begin{tabular}{|c|c|c|c|}
\hline Código & Nombre & Descripción general & Características \\
\hline B2 & $\begin{array}{l}\text { Alta densi- } \\
\text { dad de me- } \\
\text { dia altura }\end{array}$ & $\begin{array}{l}\text { Edificaciones en sector consolidado de la ciudad (tres } \\
\text { a ocho pisos), con una alta intensidad de ocupación del } \\
\text { suelo y escasa separación entre las diferentes cons- } \\
\text { trucciones. También se pueden observar en pequeñas } \\
\text { aglomeraciones peri-centrales o periféricas, de relativa } \\
\text { homogeneidad en su altura. }\end{array}$ & $\begin{array}{l}\text { Comunas asociadas: Santiago y } \\
\text { Providencia } \\
\text { Temperatura promedio: } 38^{\circ} \mathrm{C} \\
\text { Cobertura vegetal promedio: } 39 \%\end{array}$ \\
\hline B3 & $\begin{array}{l}\text { Alta densi- } \\
\text { dad de baja } \\
\text { altura }\end{array}$ & $\begin{array}{l}\text { Se presenta en conjuntos de vivienda social, viviendas } \\
\text { autoconstruidas de predios pequeños y zona urbana } \\
\text { consolidada sin edificaciones mayores a tres pisos. Las } \\
\text { viviendas tienen escasa separación y se pueden presen- } \\
\text { tar como una grilla homogénea. }\end{array}$ & $\begin{array}{l}\text { Comunas asociadas: Todas al po- } \\
\text { niente de Santiago } \\
\text { Temperatura promedio: } 38,15^{\circ} \mathrm{C} \\
\text { Cobertura vegetal promedio: } \\
42,33 \%\end{array}$ \\
\hline B5 & $\begin{array}{l}\text { Baja densi- } \\
\text { dad de me- } \\
\text { dia altura }\end{array}$ & $\begin{array}{l}\text { Está constituida por edificaciones en altura (tres y ocho } \\
\text { pisos) con una menor intensidad de ocupación del suelo } \\
\text { que las zonas de alta densidad, que por lo general se } \\
\text { complementa con jardines o parques privados. Se pue- } \\
\text { den observar en esta zona bloques de vivienda social de } \\
\text { baja intensidad de construcción, condominios cerrados } \\
\text { de edificación en altura y sectores en la zona urbana } \\
\text { consolidada reticente de ser edificada con una alta in- } \\
\text { tensidad de ocupación del suelo. }\end{array}$ & $\begin{array}{l}\text { Comunas asociadas: Las Condes y } \\
\text { Estación Central } \\
\text { Temperatura promedio: } 37,7^{\circ} \mathrm{C} \\
\text { Cobertura vegetal promedio: } 47,7 \%\end{array}$ \\
\hline B6 & $\begin{array}{l}\text { Baja densi- } \\
\text { dad de baja } \\
\text { altura }\end{array}$ & $\begin{array}{l}\text { Se materializa mediante proyectos inmobiliarios de resi- } \\
\text { dencias unifamiliares de baja intensidad de construcción, } \\
\text { condominios cerrados o agrupaciones de viviendas de } \\
\text { autoconstrucción de gran sub-división predial. }\end{array}$ & $\begin{array}{l}\text { Comunas asociadas: Las Condes, } \\
\text { La Reina y Ñuñoa } \\
\text { Temperatura promedio: } 37,6^{\circ} \mathrm{C} \\
\text { Cobertura vegetal promedio: } 55,3 \%\end{array}$ \\
\hline B9 & $\begin{array}{l}\text { Extensivo de } \\
\text { baja altura }\end{array}$ & $\begin{array}{l}\text { Edificaciones emplazadas dispersamente en el espacio, } \\
\text { con una muy baja ocupación del suelo. Se materializa } \\
\text { en parcelas de agrado y agrupaciones residenciales de } \\
\text { grandes predios. Se observa cobertura vegetal en dife- } \\
\text { rentes formas. }\end{array}$ & $\begin{array}{l}\text { Comunas asociadas: La Reina y Las } \\
\text { Condes } \\
\text { Temperatura promedio: } 36,8^{\circ} \mathrm{C} \\
\text { Cobertura vegetal promedio: } 68 \%\end{array}$ \\
\hline
\end{tabular}

Fuente: Elaboración propia. 
FIGURA 2. DISTRIBUCIÓN DE ZONAS TERMALES SELECCIONADAS Y PRECIOS DE PROPIEDADES (CASAS Y DEPARTAMENTOS).

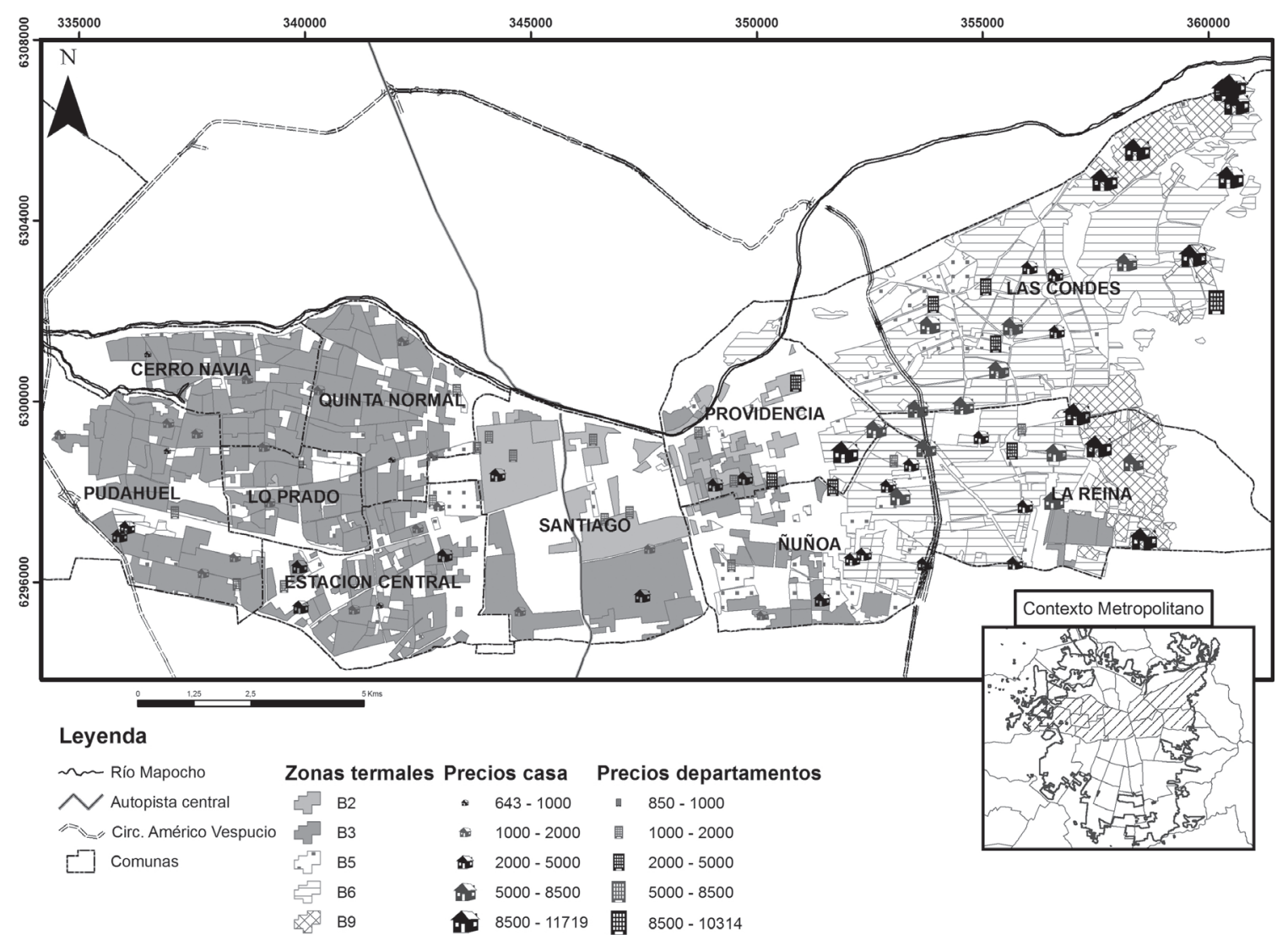

Las siglas de zonas termales significan:

(B2) Alta densidad de media altura, (B6) Baja densidad de baja altura y

(B3) Alta densidad de baja altura, (B9) Urbanización dispersa.

(B5) Baja densidad de media altura,

Fuente: Elaboración propia. 
proceso de evaluación mostraban amenos atributos ambientales. En tanto, las propiedades ofertadas en las zonas de alta densidad de media altura (B2) y alta densidad de baja altura (B3) presentan los precios promedio más bajos, siendo estas áreas las que registraron también las condiciones ambientales más precarias en su proceso de evaluación.

En la Figura 2 se observa el marcado patrón de concentración de aquellas propiedades de precios más elevados en las zonas B6 y B9, ubicadas en el sector oriente del área de estudio. Cabe mencionar que este patrón se observa tanto para casas como para departamentos.

La zona termal B2 presenta valores alrededor de $1500 \mathrm{UF}^{64}$, los cuales tienden a ser más elevados en la comuna de Providencia que en la de Santiago, lo que se relaciona tanto con la superficie del inmueble como con otros factores de localización propios de cada comuna, como por ejemplo la accesibilidad, seguridad o exclusividad. Por otro lado, las propiedades ubicadas en B3 presentan valores alrededor de 1900 UF, los cuales tienden a ser más bajos en las comunas del sector poniente. En la mayoría de los casos, la localización comunal es un factor considerable de diferenciación, que en el caso de B3 se expresa como una distribución central bastante clara para las residencias que varían entre 1100 y 2700 UF.

64 Se consideró como referencia el valor de la UF (Unidad de Fo mento) para el 2 de mayo de 2011: \$21.793.
En cuanto a baja densidad de media altura (B5), esta zona termal es la que presenta las más altas variabilidades espaciales de los precios de las propiedades, lo que se puede asociar a que las muestras ocupan propiedades de tamaños muy variables, entre 40 y $226 \mathrm{~m}^{2}$. En tanto, cabe mencionar que B5 se localiza de manera fragmentada, por lo que se constituye en la zona evaluada que registra una mayor amplitud dentro de todas las comunas en estudio, lo que está determinado por los diferentes tipos de urbanización asociados (desde viviendas sociales del tipo bloque hasta lujosos departamentos).

Respecto a B6, es en esta zona termal donde el precio promedio presenta una diferenciación sustancial respecto a las mencionadas anteriormente, situándose alrededor de 5800 UF. De todos modos existe un reducido grupo de propiedades cuyos precios coinciden con los encontrados en la zona B3. Los precios de B6 tienden a concentrarse sobre las 3800 UF.

Cabe remarcar que entre B3 y B6 se presenta una clara diferencia de precios entre las comunas. Finalmente, B9 se escapa abruptamente de los precios promedios, situándose alrededor de las 9500 UF, y presentando a su vez las superficies totales por predio más elevadas de todas las zonas. Cabe mencionar que esta zona se desarrolla sólo en el extremo oriente del área de estudio, casi 
exclusivamente en el pie de monte andino, lo que se relaciona con su condición de zona termal de mejor calidad ambiental.

\section{Publicidad inmobiliaria en el área de estudio y atributos ambientales}

La relación entre los precios de las propiedades y las condiciones ambientales es bastante estrecha, no obstante ésta por sí sola no evidencia de pleno la instrumentalización de la naturaleza urbana para dinamizar el consumo inmobiliario. Para buscar evidencias de esto se recurre a la publicidad inmobiliaria, más concretamente a aquella que posee en alguna dimensión contenido ambiental. Los proyectos evaluados se ubican, en su mayoría, dentro de las zonas evaluadas ${ }^{65}$, o bien en zonas contiguas (figura 3).

Respecto al nombre de los proyectos seleccionados (figura 3), diecisiete presentan algún sustantivo o adjetivo alusivo a condiciones ambientales, por lo general acompañado de un topónimo que da cuenta de la localización del proyecto. De este modo, la palabra que se presenta con mayor reiteración, diez en total, corresponde a "Parque", como se menciona en los proyectos "Parque Yungay", "Italiano:

65 Esto se debió a la disponibilidad de información, independiente que los casos sean representativos.
Parque Privado", "Parque Verde", "Parque Infante", "Barrio Parque Santiago", "Parque Grecia", "Entre Parques", "Eco Parque", "Parque Real" y "Parque Estación". La utilización del nombre "Parque" se puede relacionar con una clara connotación de un espacio artificialmente dotado de naturaleza, emplazado dentro de un espacio urbano consolidado, que en sí mismo contiene las nociones de asentamiento, naturaleza y esparcimiento. Parte de estos proyectos se emplazan en zonas B5 y B6, y suelen hacer alusión a parques que no son propios al proyecto, que producen una internalización de las buenas condiciones ambientales propias de B5 y B6. El uso de este nombre denota, en forma concisa, una invitación por parte del oferente inmobiliario para habitar un inmueble inserto dentro de un espacio cargado de naturaleza pero sin descontextualizarse de la matriz urbana en la cual se encuentra situado.

Un rol publicitario similar al de "Parque" juega el término "Jardín", como se menciona en los proyectos "Jardín de Luz", "Jardines de Vespucio", "Jardín San Isidro Centro" y "Jardines de Almeyda". Pese a ser similar a "Parque", "Jardín" se puede asociar a diferentes condiciones. En sí misma la palabra alude a la existencia de cultivos vegetales, pero exclusivamente enfocados a fines ornamentales, y por ende su valoración pasa por algo más estético que 
FIGURA 3. DISTRIBUCIÓN DE ZONAS TERMALES SELECCIONADAS, PUNTOS DE MUESTREO PARA PRECIOS DE PROPIEDADES (CASAS Y DEPARTAMENTOS) Y LAS MUESTRAS PARA PUBLICIDAD INMOBILIARIA.

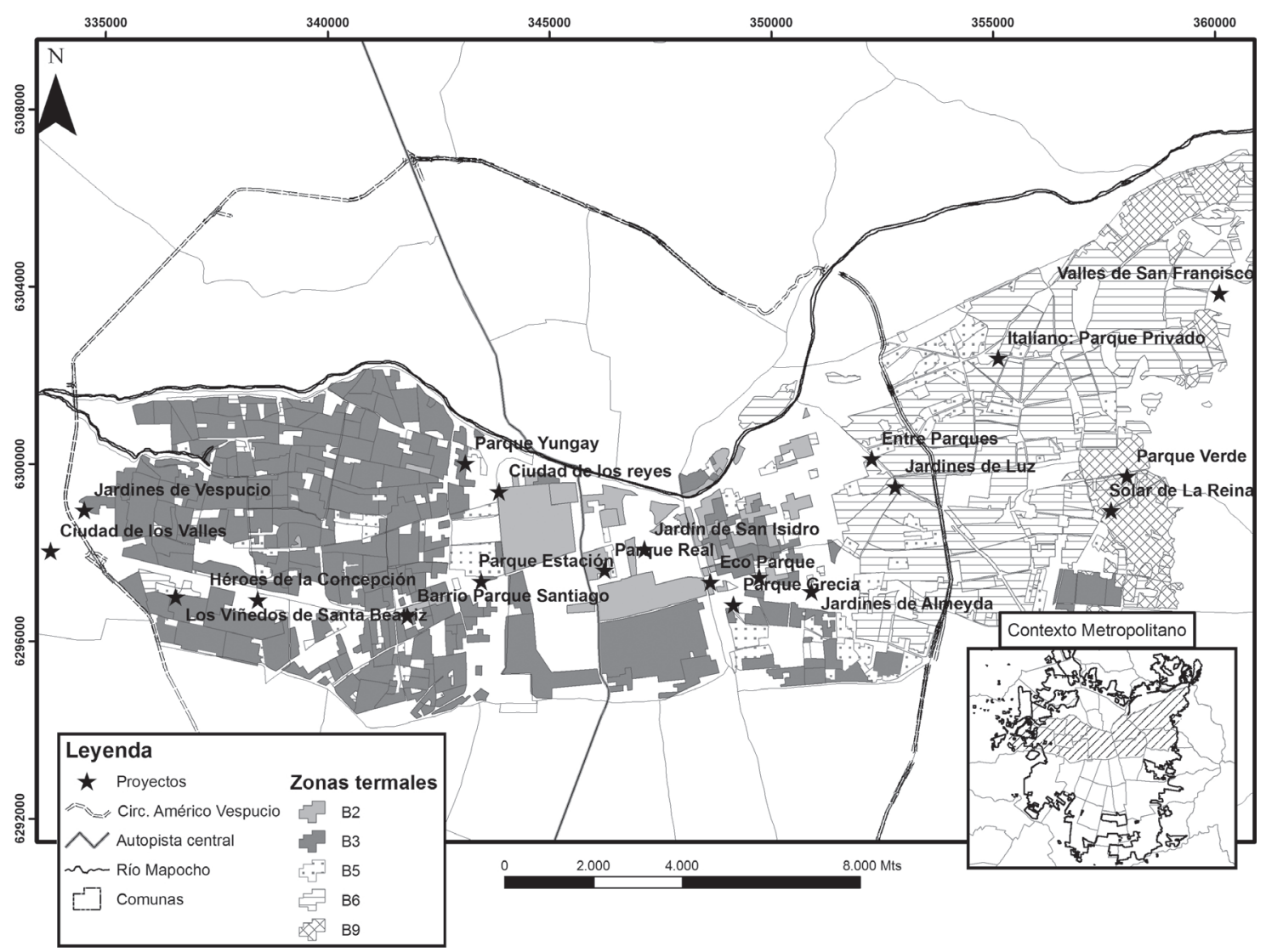

Las siglas de zonas termales significan:
(B2) Alta densidad de media altura, (B6) Baja densidad de baja altura y
(B3) Alta densidad de baja altura,
(B5) Baja densidad de media altura,
(B9) Urbanización dispersa.
Fuente: Elaboración propia.

92 revista invi № 75 / Agosto 2012 / Volumen N ํo 27: 73-103 
funcional. Por lo tanto, se puede interpretar que el oferente inmobiliario en este caso apunta a vivir en un espacio dotado de naturaleza, reconociendo explícitamente su elaboración artificial y con una finalidad concreta, que brindará al espacio estética paisajística y belleza, como servicios ambientales fundados en la naturaleza. En esos espacios de alto valor estético también se pueden desenvolver otras satisfacciones, como por ejemplo la validación como clase de estatus social alto.

Por otro lado se presentan los proyectos que aluden a condiciones de naturaleza que dan cuenta de manera más radical del rechazo de la vida urbana. Ejemplo de esto son aquellos nombres que mantienen la lógica de estar acompañando a algún topónimo, que evoca conceptos poco comunes para la vida urbana, por ejemplo "Valle San Francisco", "Los Viñedos de Santa Beatriz" o "Ciudad de los Valles". Estos proyectos se emplazan en la periferia de Santiago (figura 3) y representan grandes extensiones superficiales. Se asocian a zonas B6 o B9, pues las buenas condiciones ambientales en ellos son un atributo fundamental. Relacionado con esto último se desprende que estos proyectos no sólo empleen conceptos alusivos a la naturaleza, sino también a conceptos que difícilmente se asocian a las formas de vida urbana propias de Santiago.

En cuanto a los atributos que ofrecen los proyectos, del total se encontró en quince de ellos a componentes ambientales naturales. Estos suelen enunciar conceptos asociados a naturaleza de dos modos diferentes. En primer lugar se encuentran aquellos proyectos que indican la existencia de parques, áreas verdes o plazas, ocho en total, como un atractivo más de las áreas residenciales. En segundo lugar, están aquellos proyectos que enuncian estas condiciones de un modo discursivo, siete en total, los cuales no sólo los mencionan sino que además decididamente invitan a vivir en entornos naturales y todo lo que estos ofrecen.

Dentro del primer caso, se consideran condiciones ambientales de diferentes modos, pero siempre como objetos o productos materiales e inmateriales que integran el proyecto inmobiliario completo, tales como áreas verdes, seguridad, accesibilidad o plusvalía, sólo por nombrar algunas. El producto mayormente asociado a naturaleza es el de "áreas verdes", y en menor medida el de "Jardín".

Dentro del segundo grupo, si bien la tónica continúa siendo la de incentivar el vivir cerca de componentes naturales, la promoción de los proyectos en un marco discursivo apunta a realizar una invitación a un modo de vida cercano a la naturaleza, más que a reconocer las condiciones naturales del proyecto en sí mismas. Empero, no se debe olvidar que los atributos ambientales (parques, jardines, áreas verdes o árboles) son un eje fundamental al promover los proyectos relacionados a entornos naturales. Por ejemplo en "Parque Verde": 
"Vivir en La Reina, rodeado de la naturaleza y cerca de todo... con una agradable calle interior arbolada y con acceso controlado" (Sitio web "Parque Verde", Inmobiliaria Cunaco S.A.).

Aquí se hace un ofrecimiento a vivir rodeado de naturaleza, y se desprende que esto materialmente responde al arbolado de la calle interior. En efecto, si la afirmación "rodeado de naturaleza" pretende representar buenas condiciones ambientales, el proyecto se emplaza en una zona B9, la que presentó los mejores atributos ambientales y los precios más elevados. No se debe dejar de hacer mención a que este proyecto se localiza en el pie de monte, por lo tanto, en este caso el oferente inmobiliario emplea como atributo una condición propia del paisaje natural, apropiándose de condiciones que no le pertenecen. El estar "rodeado de naturaleza" también se puede asociar a que en la comuna de La Reina se presentan buenas condiciones ambientales en general.

Asimismo, algunos proyectos ofrecen sus propios "parques" como un atributo fundamental de sus iniciativas:

"Vivir en una tradicional ubicación de Ñuñoa y a la vez inmerso en un espectacular parque, ya no es un sueño" (Ficha "Parque Infante", Inmobiliaria ICOM).

"Barrio Parque Santiago es un proyecto con hermosas áreas verdes inmersas en un gran parque, ubicado a una cuadra del metro Las Rejas" (Ficha "Barrio Parque Santiago", Inmobiliaria Barrio Parque).
Estos parques insertos dentro de los proyectos son de absoluto carácter privado, por lo que su presencia en zonas de diferentes condiciones ambientales no genera mayores aportes al entorno, dado que los espacios naturales no son de libre acceso y su disposición fragmentada no realiza contribuciones significativas a las dinámicas ecológicas. Se debe señalar que estos proyectos se asocian más a zonas B2, B3 o B5, lo que toma sentido si se considera que la explotación de las condiciones ambientales se centra en los elementos propios del proyecto, y no en los del entorno.

Se debe hacer una distinción respecto al proyecto "Entre Parques", dado que si bien mantiene la intención de promover condiciones ambientales como un instrumento de consumo, en este caso se utilizan los parques públicos para este fin:

"En uno de los sectores más exclusivos y tradicionales de Providencia se ubica Entre Parques, un proyecto rodeado de extensas áreas verdes que conforman la Plaza Las Lilas y el Parque Pocuro" (Ficha "Entre Parques", Penta Inmobiliaria).

Esto da cuenta, al igual que en el proyecto "Parque Verde", de un apoderamiento de condiciones que no son propias ni exclusivas del proyecto, sino que involucran espacios públicos, incluyendo condiciones ambientales del entorno, como elementos que tornan publicitariamente más atractivos los proyectos inmobiliarios. De modo muy similar el proyecto "Valle San Francisco", emplazado en el 
pie de monte de Las Condes (homologable a B9), también se apropia de su entorno natural y valora su aislamiento y panorámicas del paisaje:

"Un exclusivo condominio, rodeado de naturaleza, con amplias áreas verdes, accesos controlados las 24 hrs. y una vista única al valle de Santiago" (Folleto "Valle San Francisco", Inmobiliaria Aconcagua).

La distinción de "Valle San Francisco" frente a "Entre Parques" y a "Parque Verde", es que este proyecto no sólo se apropia de las condiciones ambientales del entorno, sino que además las fomenta y consolida mediante áreas verdes, lo que dentro de los atributos ambientales presenta un doble atractivo, en la medida que las ofrece dentro de un entorno que ya las posee, como es el pie de monte, y especialmente la comuna de Las Condes. Así, proyectos de esta índole ayudan a consolidar las condiciones ambientales características de su entorno (B6 y B9).

Otro caso es el de "Ciudad de Los Valles", dado que se emplaza en una comuna que por lo general no es reconocida por sus condiciones ambientales favorables (Pudahuel); no obstante, toma las condiciones de espacio periférico no urbanizado completamente para señalar la transición entre la ciudad y la naturaleza y se apropia de condiciones ambientales que carecen de sustento científico:

"El espectacular MEGAPROYECTO CIUDAD DE LOS VALLES se ha consolidado como un sector residencial único, a pocos minutos del Centro de Santiago pero con todas las ventajas de estar inserto en un entorno natural que nos conecta con la naturaleza y ajena a toda contaminación" (Sitio web "Ciudad de los Valles", Inmobiliaria GA).

Se puede leer que se emplea la "conexión con la naturaleza" y lo "ajeno a la contaminación" como un atributo, lo cual se complementa con un entorno natural creado por el proyecto para la promoción. De este modo se recogen las condiciones ambientales, la exclusividad y la conectividad para promover lo que la inmobiliaria señala como "entorno ideal":

"Haga de todos sus momentos, instantes únicos, disfrutando desde hoy las múltiples ventajas y comodidades que sólo ofrece un proyecto inmobiliario emplazado estratégicamente y en un entorno ideal" (Sitio web "Ciudad de los Valles", Inmobiliaria GA).

El "Megaproyecto Ciudad de Los Valles" se plantea como un espacio urbano autónomo segregado y privado, por lo que utiliza el término "Ciudad" en su nombre. Se trataría del acceso a espacios naturales por parte de los habitantes de una comuna que no los posee y que mayormente no se ve potenciada con proyectos como el mencionado.

En cuanto a las imágenes publicitarias de los proyectos, dieciséis presentan símbolos que se pueden asociar a condiciones ambientales. Estos se pueden desglosar en tres grupos: tres de ellas basan sus representaciones en los atributos ambientales 
del entorno; cinco lo hacen en las condiciones ambientales de la propuesta inmobiliaria y ocho en las condiciones ambientales del entorno como en las del proyecto.

En cuanto a aquellos proyectos que en su publicidad ilustran las condiciones ambientales del entorno, se puede distinguir "Parque Real". Su cartografía de ubicación (figura 4) resalta en tonalidades verdes el Parque Almagro y el Paseo Bulnes. Para estos casos se fomenta el consumo mediante las condiciones ambientales del entorno, resaltándolas en las imágenes, lo que da cuenta de un interés concreto por parte del oferente de que el receptor se percate de dichas condiciones. Quizás algo central de este hecho sea que las condiciones ambientales de Santiago centro no destacan por sí solas (B2, B3 o B5), por lo que realzar la existencia de estos parques podría actuar como una estrategia para mejorar la representación de la comuna en términos ambientales. Es importante precisar que el Paseo Bulnes es más un paseo peatonal que un corredor verde como se ilustra en la publicidad. No obstante, las áreas verdes ofrecidas por el proyecto son de uso público, lo que da cuenta de la internalización de las condiciones ambientales del entorno.

Respecto a aquellos proyectos que resaltan en sus imágenes publicitarias fundamentalmente sus condiciones ambientales se puede destacar "Parque Yungay" (figura 6). En éste se muestra al centro del aviso publicitario una fotografía del proyecto que ocupa casi la totalidad del folleto, la cual presenta las edificaciones en contacto con un cielo azul claro y en la parte baja una gran cantidad de áreas verdes de mucha notoriedad en la imagen. Esto se complementa con el texto que asegura la existencia de $4.400 \mathrm{~m}^{2}$ de áreas verdes. Lo "verde" o "puro" se muestra como algo central en el proyecto inmobiliario, siendo un incentivo central para adquirir viviendas en áreas residenciales que no se caracterizan mayormente por sus atributos ambientales. Lo predominante en el entorno de "Parque Yungay" es B3, y en menor medida zonas B6 que se pueden asociar con un aumento en la cantidad de proyectos inmobiliarios de este tipo.

La mayor parte de los proyectos evaluados contempla en sus imágenes publicitarias atributos ambientales, tanto de las condiciones de los proyectos, como en cuanto a las condiciones de su entorno. En general los proyectos que ilustran condiciones ambientales propias y del entorno dan cuenta de que en la mayoría de los casos se hace más énfasis en los entornos mismos que en las edificaciones, lo que ilustra el gran interés de los vendedores por convencer a sus clientes que habitarán espacios dotados de buenas condiciones ambientales, llegando incluso a ofrecer éstas para entornos que no las poseen. Se puede destacar el proyecto "Valle de San Francisco", ya que 
FIGURA 4. IMAGEN PUBLICITARIA DE “PAROUE REAL”.

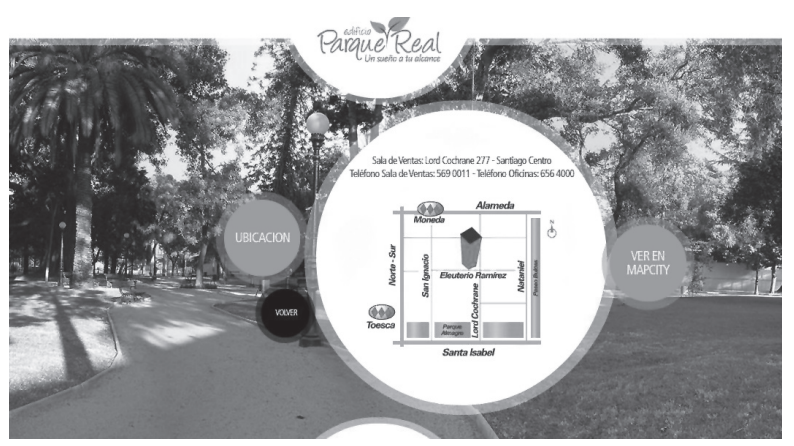

Fuente: www.parque-real.cl/.

FIGURA 6. IMAGEN PUBLICITARIA DE "PARQUE YUNGAY".

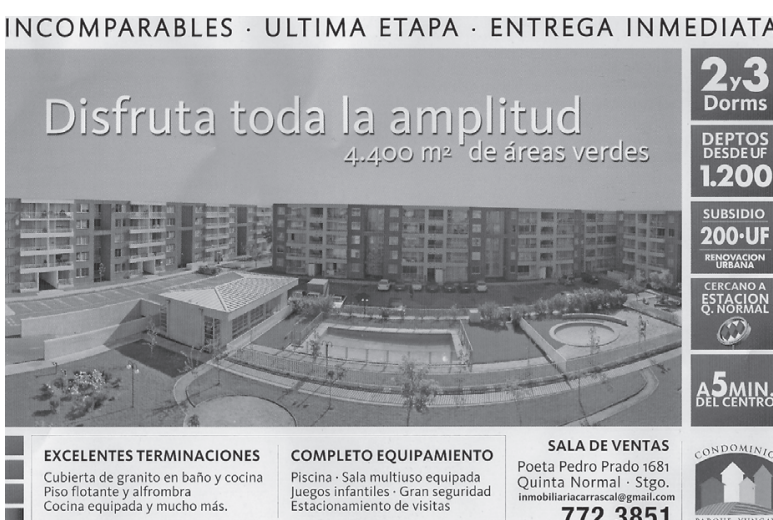

Fuente: Digitalizado en base a folleto publicitario.
FIGURA 5. IMAGEN PUBLICITARIA DE "VALLE DE SAN FRANCISCO".

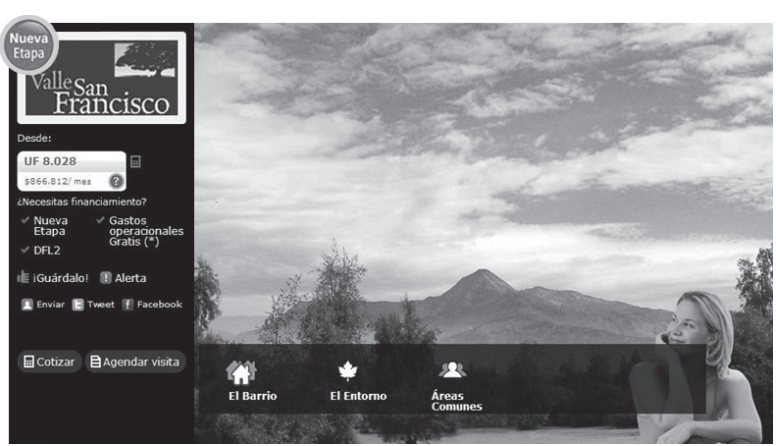

Fuente: www.iaconcagua.cl.

FIGURA 7. IMAGEN PUBLICITARIA DE “VALLE DE SAN FRANCISCO".

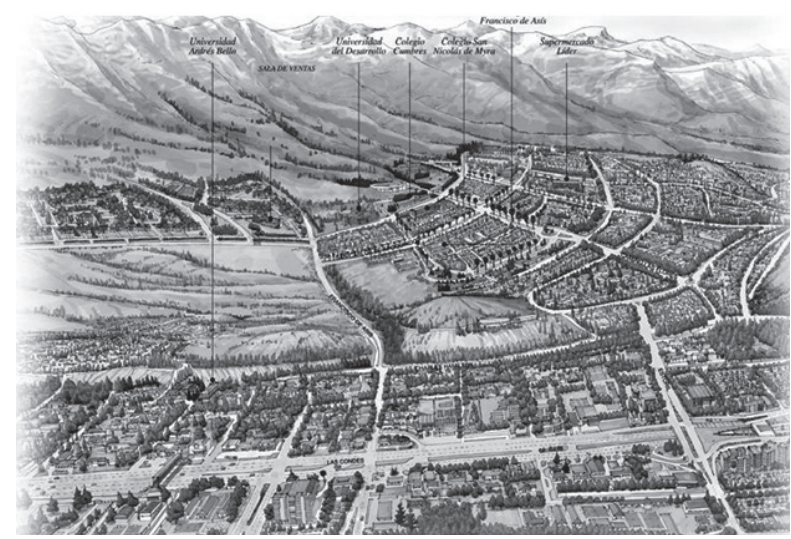

Fuente: www.iaconcagua.cl. 
es el que más explota los atributos ambientales entre los proyectos analizados. Se puede observar en la figura 5 cómo se plantean las viviendas con una gran cantidad de áreas verdes, tanto privadas como colectivas, dotadas de césped, árboles y flores, contextualizadas en un pie de monte bastante vegetado con especies arbustivas. También se puede observar a una sonriente mujer, acompañada en segundo plano por el claro de una aglomeración arbórea desarrollada, y con una cordillera bastante vegetada en tercer plano, acompañada de un cielo azul. Es importante mencionar la ilustración de ubicación del proyecto (figura 7), donde es el color verde el predominante y se muestran vastos espacios no urbanizados provistos de cobertura vegetal. Los espacios urbanizados publicitados son de muy baja densidad y presentan grandes áreas verdes, siempre acompañados de árboles dispuestos en una alineación regularmente uniforme y disciplinada. En relación con las zonas termales, permite pensar que el oferente conoce absolutamente los atributos ambientales de B6 y B9, pues la figura 7 las ilustra desde una perspectiva panorámica.

\section{Conclusiones}

Los resultados obtenidos del análisis exploratorio sobre los valores de las propiedades por zona termal permiten identificar una relación clara entre estas dos variables. La relación entre los valores económicos de las propiedades y las zonas termales, señala que las asociadas a temperaturas menores y mayor porcentaje de cobertura vegetal, es decir de mejor calidad ambiental, tienden a presentar valores considerablemente más elevados en el mercado. Se pueden desprender dos observaciones. Primero, para acceder a la compra de una propiedad en las zonas de mejor calidad ambiental dentro del área de estudio, se debe desembolsar una gran cantidad de dinero; en segundo lugar, se puede pensar que los proyectos inmobiliarios de alto valor, producen y consolidan estas zonas de alta calidad ambiental en la medida que construyen viviendas espaciosas con gran cantidad de áreas verdes. Si bien esto último no es determinado en la presente investigación, el análisis de la publicidad inmobiliaria da cuenta de un interés por parte del sector privado de ofertar estas condiciones, y consiguientemente, un interés por parte de los consumidores, de acceder a éstas. Además se puede decir que la instrumentalización de la naturaleza, o bien de las áreas verdes, en el AMS no es producto exclusivo de las urbanizaciones cerradas. Es más, es un factor constitutivo de una gran cantidad de proyectos inmobiliarios.

El análisis de publicidad inmobiliaria fue un aporte para confirmar la valoración que otorga el sector inmobiliario y los consumidores a las condiciones ambientales. Si bien académicamente se reconocen varias amenidades como parte de las condiciones 
ambientales, en términos prácticos la publicidad inmobiliaria se orienta más a valorarlas como algo estético y por su connotación como lugar de esparcimiento y recreación. Aunque no se puede dar cuenta de una mercantilización de las condiciones ambientales tras la presente investigación, ésta se asoma como algo evidente tras estar relacionada con los valores de las propiedades, y especialmente al ser internalizadas como áreas verdes y amplios jardines en la publicidad inmobiliaria. Por lo tanto, no se puede hablar de una mercantilización de las condiciones ambientales o del comportamiento climático per se, sino que sería más adecuado afirmar que los factores que determinan éstas podrían encontrarse mercantilizados en la medida que operan como instrumentos de consumo. Sin duda, esta aseveración es la que adquiere mayor firmeza durante el presente artículo.

Las representaciones materializadas en la publicidad inmobiliaria dan cuenta de dos dimensiones. Primero es el mensaje que buscan instaurar en la población mediante el ofrecimiento de proyectos nuevos basados en espacios verdes. Como sostienen varios autores, el rol de los medios de comunicación es central en el proceso de instauración del imaginario, siendo partícipes activos de la construcción cultural. No obstante, y en la segunda dimensión por señalar, la publicidad inmobiliaria también debe apelar a aquellos valores que se encuentran en la población, de lo contrario no podrían incentivar el consumo. Por ende, la publicidad inmobiliaria en realidad da cuenta tanto de una construcción de la cultura existente en la población, así como consecutivamente van construyendo la ciudad que mejor se acopla a las relaciones de mercado.

Es fundamental perfilar investigaciones desde marcos teóricos y metodológicos amplios para comprender los diferentes procesos que se dan actualmente en las ciudades contextualizadas en el capitalismo. No se puede desentender que la ciudad es un espacio cargado de intencionalidad, así como su materialidad representa el ejercicio del poder político, económico y social. Del mismo modo se puede apreciar que desde la morfología urbana se observan diferentes procesos económicos, sociales y políticos, los cuales constituyen un espacio urbano creado en base a estos procesos de forma complementaria al plano imaginario.

\section{Bibliografía}

CAPEL, Horacio. La morfología de las ciudades: I. Sociedad, cultura y paisaje urbano. Barcelona, España, Ediciones del Serbal. 2002. 543 p. ISBN 84-7628-391-1.

CÁCERES, Pablo. Análisis cualitativo de contenido: Una alternativa metodológica alcanzable. Psicoperspectivas. Revista Escuela de Psicología UCV. 2: 53-82. 2003. ISSN 0718-6924.

revista invi № 75 / Agosto 2012 / Volumen N ํo 27: 73-103 
DEMATTEIS, Giuseppe. Suburbanización y periurbanización. Ciudades anglosajonas y ciudades latinas. En MONCLÚS, Francisco, ed. La ciudad dispersa. Barcelona, España. Centre de Cultura Contemporània de Barcelona. 1998. p. 17-34. ISBN 84-88811-35-7.

ESCOBEDO, Francisco; NOWAK, David; WAGNER, John; DE LA MAZA, Carmen; RODRÍGUEZ, Manuel; CRANE, Daniel y HERNÁNDEZ, Jaime. The socioeconomics and management of Santiago de Chile's public urban forests. [En línea]. Urban Forestry \& Urban Greening. 4(3-4):105-114. 2006. ISSN: 1618-8667. Disponible en http://dx.doi. org/10.1016/j.ufug.2005.12.002.

FUENTES, Claudio; IRARRÁZAVAL, Felipe; ROMERO, Hugo y SALGADO, Marcela. Comodificación y segregación socio-ambiental en Peñalolén: Comprendiendo su estructuración territorial. Revista Sociedad y Equidad. 1: 1-29, enero 2011. ISSN: 0718-9990.

FRYKMAN, Jonas y LÔFGREN, Orvar. The nature lovers. En: FRYKMAN, Jonas y LÔFGREN, Orvar. Culture builders: A historical anthropology of middle class life. Estocolmo, Liberforlang. 1987. p. 42-87. ISBN 978-0813512396.

GIROLA, María. Imaginarios urbanos en zonas verdes y zonas rojas de la Región Metropolitana de Buenos Aires. Cuadernos de Antropología Social. (20): 93-111, diciembre 2004. ISSN 1850-275X.

GUERRA, Luisa. Evaluación ambiental de la tierra vacante del área metropolitana del Gran Santiago y su relación con los grupos socioeconómicos de la población y el valor del suelo. Facultad de Arquitectura y Urbanismo. Universidad de Chile. 2009. Memoria para optar al Título Profesional de Geógrafo.

HARVEY, David. Los límites del capital y la teoría marxista. Mexico D.F, Fondo de Cultura Económica, UNAM. 469 p. 1990. ISBN 968-16-3302-4.

HARLAN, Sharon; BRAZEL, Anthony; PRASHAD, Lela; STEFANOV, William y LARSEN, Larissa. Neighborhood microclimates and vulnerability to heat stress. [En línea]. Social Science \& Medicine. 63(11): 2847-2863, septiembre 2006. ISSN: 02779536. Disponible en http://dx.doi.org/10.1016/j. socscimed.2006.07.030.

HEYNEN, Nick. Green urban political ecologies: toward a better understanding of inner-city environmental change. [En línea]. Environment and Planning A. 38(3): 499 - 516. 2006. ISSN: 0308-518X. Disponible en http://www.envplan.com/epa/fulltext/ a38/a37365.pdf.

HIERNAUX, Daniel. Los imaginarios urbanos: de la teoría y los aterrizajes en los estudios urbanos. [En línea]. Eure. 99(33): 17-30, agosto 2007. ISSN 07176236 Disponible en: http://dx.doi.org/10.4067/ S0250-71612007000200003.

JANOSCHKA, Michael. El nuevo modelo de la ciudad latinoamericana: Fragmentación y privatización. [En línea]. EURE. 28(85): 11 - 29, diciembre 2002. ISSN 0717-6236. Disponible en: http:// dx.doi.org/10.4067/S0250-71612002008500002. 
MARANS, Robert. Understanding environmental quality through quality of life studies: the 2001 DAS and its use of subjective and objective indicators. [En línea]. Landscape and Urban Planning 65(1-2): 73-83, noviembre 2003. ISSN: 01692046. Disponible en: http://dx.doi.org/10.1016/ S0169-2046(02)00239-6.

MATTOS, Carlos de. Santiago de Chile: Metamorfosis bajo un nuevo impulso de modernización capitalista. En: MATTOS, Carlos de; DUCCI, María Elena; RODRÍGUEZ, Alfredo y YÁÑEZ, Gloria, eds. Santiago en la globalización: ¿Una nueva ciudad? Santiago, Chile, Ediciones SUR y Libros EURE. 2004. p. 17-46. ISBN 956-208-072-2.

MELIZIA, Matilde. Enfoque teórico y conceptual para el estudio de las urbanizaciones cerradas. [En línea]. Andes. 22(2), diciembre 2011. ISSN 1668-8090. Disponible en: http://www.scielo. org.ar/scielo.php?script=sci_arttext $\&$ pid=S1668$80902011000200005 \& \operatorname{lng}=$ es $\&$ nrm $=$ iso.

MELLIZO, Carlos. Prólogo. En: MILL, Jonh. S. La Naturaleza. Madrid, España, Alianza. 1998. 95 p. ISBN 84-206-3505-7.

MILLER, Robert. Planeación del enverdecimiento urbano. En: KRISHNAMURTHY, L. y RENTE NASCIMENTO, José, eds. Áreas Verdes Urbanas en Latinoamérica y el Caribe. Chapingo, México, Universidad Autónoma de Chapingo. 1997. p. 83108. ISBN 968-884-491.

MOLINA, Melandra; ROMERO, Hugo y SARRICOLEA, Pablo. Características socio ambientales de la expansión urbana de las Áreas metropolitanas de Santiago y Valparaíso. En: HIDALGO, Rodrigo; MATTOS, Carlos de y ARENAS, Federico, eds. Chile: del país urbano al país metropolitano. Santiago, Chile. 2009. p. 187-200. ISBN 978956-1410-541. Serie Geolibros Nº12 y Colección Eurelibros.

MÜLLAUER-SEICHTER, Waltraud. El uso del espacio verde urbano: entre lo privado y lo público, estética y rendimiento económico. La Casa de Campo, Parque de Madrid. Revista de Dialectología y Tradiciones Populares. 56(1): 163-181, 2001. ISSN 1988-8457.

LERDA, Sandra y SABATINI, Francisco. De Lo Errázuriz a Til-Til: El problema de la disposición final de los residuos sólidos domiciliarios de Santiago. [En línea]. Santiago, Departamento de Ingeniería Industrial, Universidad de Chile. 1996. Serie Estudios de Casos No 8. Disponible en: http:// www.mgpp.cl/wp-content/uploads/2011/04/ CASO081.pdf.

LÓPEZ, Liliana. Tijuana: imaginarios globales, fortificaciones locales. Sociológica. (66): 121-153, mayo 2008. ISSN 0187-0173.

PEÑA, Marco A. Relationships between remotely sensed surface parameters associated with the urban heat sink formation in Santiago, Chile. [En línea]. International Journal of Remote Sensing. 29(15): 4385 - 4404. 2008. ISSN: 0143-1161. Disponible en: http://dx.doi.org/10.1080/01431160801908137.

PERKINS, Harold y HEYNEN, Nick. Inequitable access to urban reforestation: the impact of urban political economy on housing tenure and urban

revista invi № 75 / Agosto 2012 / Volumen № 27: 73-103 101 
forests. [En línea]. Cities. 21(4): 291-299, 2004 ISSN: 0264-2751. Disponible en: http://dx.doi. org/10.1016/j.cities.2004.04.002.

REYES, Sonia y FIGUEROA, Isabel. Distribución, superficie y accesibilidad de las áreas verdes en Santiago de Chile. [En línea]. EURE. 36(109): 89-110, diciembre 2010. ISSN 07176236. Disponible en: http://dx.doi.org/10.4067/ S0250-71612010000300004.

REYES, Sonia. Santiago: La difícil sustentabilidad de una ciudad neoliberal. En: MATTOS, Carlos de DUCCI, María Elena; RODRÍGUEZ, Alfredo y YAÑEZ, Gloria, eds. Santiago en la globalización: ¿Una nueva ciudad? Santiago, Chile, Ediciones SUR y 2004. p. 17-46. ISBN 956-208-072-2. Libros EURE.

RíOS, Diego y PÍREZ, Pedro. Urbanizaciones cerradas en áreas inundables del municipio de Tigre: iproducción de espacio urbano de alta calidad ambiental? [En línea]. EURE. 34(101): 99-119, marzo 2008. ISSN 07176236. Disponible en: http://dx.doi.org/10.4067/ S0250-71612008000100005

ROMERO, Hugo; FUENTES, Claudio y SMITH, Pamela. Ecología política de los riesgos naturales y de la contaminación ambiental en Santiago de Chile: necesidad de justicia ambiental. [En línea]. Scripta Nova. 14(331), 2010. Disponible en: http://www.ub.edu/geocrit/sn/sn-331/sn-33152.htm.
ROMERO, Hugo y VÁSQUEZ, Alexis. La comodificación de los espacios urbanizables y la degradación ambiental en Chile. [En línea]. Scripta Nova. 9(194), 2005. Disponible en: http://www.ub.edu/geocrit/ sn/sn-194-68.htm

SALGADO, Marcela. Segregación socioambiental en la comuna de Peñalolén, Santiago de Chile. Tesis presentada al Departamento de Posgrado y Postítulo, Programa Interfacultades de la Universidad de Chile para optar al título de Magíster en Planificación y Gestión Ambiental. Santiago, Chile. 2010.

SANTOS, Milton. Por otra globalización: del pensamiento único a la conciencia universal. Bogotá, Colombia, Edición Convenio Andrés Bello. 2004. 140 p. ISBN 958-698-151-7.

SMITH, Neil. Nature as accumulation strategy. Socialist register. (43): 1-21, 2007. ISSN 0081-0606.

STEWART, lain y OKE, Tim. Newly developed "thermal climate zones" for defining and measuring urban heat island magnitude in the canopy layer. EN: International Conference on Urban Climate (7a, 2009, Yokohama, Japan). The seventh International Conference on Urban Climate. International Association for Urban Climate, 29 June - 3 July 2009

SWYNGEDOUW, Erik y HEYNEN, Nick. Urban political ecology, Justice and the politics of scale. [En línea]. Antipode. 35(5): 898-918, 2003. ISSN 0066-4812. Disponible en: http://dx.doi. org/10.1111/j.1467-8330.2003.00364.x. 
TRIVELLI, Pablo. Sobre el debate acerca de la política urbana, la política del suelo y la formación de los precios de la tierra urbana en el Gran Santiago, antecedentes teóricos y empíricos. Boletín Mercado del Suelo Urbano Área Metropolitana de Santiago. (97), 2006.

VÁSQUEZ, Alexis. Vegetación urbana y desigualdades socioeconómicas en la comuna de Peñalolén, Santiago de Chile. Una perspectiva de justicia ambiental. Tesis presentada al Departamento de Posgrado y Postítulo, Programa Interfacultades de la Universidad de Chile para optar al grado de Magíster en Gestión y Planificación Ambiental. Santiago, Chile. 2008. 